\title{
Ecocardiografía en reanimación cardiopulmonar
}

\section{Echocardiography in cardiopulmonary resuscitation}

\author{
Cristian Villanueva C. ${ }^{1}$, Paulina Castillo S. ${ }^{2}$, Fernando Aranda G. ${ }^{3}$
}

\begin{abstract}
Cardiac arrest is a clinical entity that is frequently found in emergency services and critically ill units, with cardiopulmonary resuscitation (CPR) techniques being an integral part of the core training of each emergency medical provider. The use of focused cardiac ultrasound (FoCUS) is a cost-effective adjunctive tool for the management of CPR in the hospital environment. The literature supports its value as a prognostic examination of negative survival in the absence of spontaneous cardiac movements, asystole and true pulseless electrical activity (PEA). In addition, it includes a positive prognostic factor for recovery from spontaneous circulation (ROSC) and hospital survival in pseudo-PEA. The FoCUS will allow the limited and early diagnosis of reversible causes of PCR in non-defibrillable rhythms and, subsequently, guide and evaluate the therapeutic measures used during CPR. Serial evaluation by echocardiography after ROSC can guide treatment and establish prognosis in these patients.
\end{abstract}

\section{RESUMEN}

El Paro Cardiorrespiratorio (PCR) es una entidad clínica que se encuentra con frecuencia en los servicios de urgencia y unidades de paciente crítico siendo las técnicas de reanimación cardiopulmonar (RCP) una parte integral de la capacitación central de cada proveedor de atención médica de emergencia. El uso de ecocardiografía focalizada (FoCUS) es una herramienta coadyuvante costo-efectiva para el manejo de PCR en el ambiente hospitalario. La literatura avala su valor como examen pronóstico de sobrevida negativo ante ausencia

\section{Key words:}

Echocardiography, cardiac arrest,

POCUS,

FoCUS,

recovery of spontaneous circulation

\section{Palabras clave:}

Ecocardiografía, paro cardiorrespiratorio, POCUS,

FoCUS,

recuperación de la circulación espontánea

Residente de Anestesiología y Reanimación, Universidad de Valparaíso.

2 Anestesióloga, Hospital Eduardo Pereira.

3 Jefe Cátedra de Anestesiología y Reanimación, Universidad de Valparaíso.

Fecha de recepción: 10 de septiembre de 2020

Fecha de aceptación: 25 de noviembre de 2020

\section{ORCID}

0000-0002-5460-960X

\section{Correspondencia:}

Cristian Villanueva C.

cristian.meduv@gmail.com 
de movimientos cardiacos espontáneos, asistolia y actividad eléctrica sin pulso (AESP) verdadera. Además, incluye un factor pronóstico positivo de recuperación de la circulación Espontánea (RCE) y sobrevida hospitalaria en pseudoAESP. El FoCUS permitiría el diagnóstico acotado y precoz de causas reversibles de PCR en ritmos no desfibrilables y, subsecuentemente guiar y evaluar las medidas terapéuticas empleadas durante la RCP. La evaluación seriada mediante ecocardiografía tras RCE permite guiar el tratamiento y establecer pronóstico en estos pacientes.

\section{Introducción}

E I paro cardiorrespiratorio (PCR) es una entidad clínica que se encuentra con frecuencia en las Unidades de Emergencia de Adultos y las técnicas de reanimación cardiopulmonar (RCP) constituyen una parte integral de la capacitación central de cada proveedor de atención médica de emergencia. La RCP en el servicio de urgencias es un evento importante que moviliza la sala de reanimación y requiere una rápida toma de decisiones y una intervención sistemática[1]. Según las estadísticas de la American Heart Association de 2013, la tasa de sobrevida global al alta hospitalaria fue de $9,5 \%$ y de $23,9 \%$ para el PCR extrahospitalario e intrahospitalario, respectivamente[1]. La asistolia extrahospitalaria tiene el peor pronóstico con una tasa de supervivencia de solo $2 \%-7 \%[2]$.

Es práctica habitual en varios servicios de urgencias y hospitales adoptar un tiempo promedio de 20 minutos de RCP como mínimo a realizar antes de su finalización, a pesar de la falta de evidencia para este punto de corte[3]. Además, es una preocupación común asignar un tiempo estándar a todas las reanimaciones y que esta pueda dejar a algunos pacientes con una atención subóptima, pero es más inquietante basar esta interrupción prematura solamente en herramientas clínicas limitadas y a veces subjetivas.

Se han estudiado varios factores asociados con el pronóstico en pacientes cursando con un PCR: reportándose un mejor pronóstico en pacientes con ritmo inicial desfibrilable, RCP inicial por transeúntes, PCR presenciado y en pacientes conscientes al ingreso[4],[5]. Se ha comprobado también que pacientes con un end tidal de $\mathrm{CO}_{2}$ superiores a $10 \mathrm{mmHg}$ tienen mejores resultados. Sin embargo, no hay predictores totalmente precisos que puedan determinar definitivamente qué pacientes tendrán retorno de circulación espontánea (RCE) y cuáles no[6],[7]. Durante los últimos años la literatura ha revelado que el ultrasonido focalizado (PoCUS) en el paro cardíaco puede agregar un valor pronóstico significativo al examen clínico dis- ponible actualmente[8]. La aplicación de la ecografía en el paro cardíaco se ha expandido ampliamente y se ha convertido en una habilidad central reconocida por muchas organizaciones internacionales[9],[10]. Así, una de las aplicaciones de la ecografía en el paro cardíaco consiste en identificar la ausencia total de movimiento cardíaco, denominada Parada Cardíaca, en la cual, la literatura actual ha demostrado una probabilidad muy baja de supervivencia.

\section{Consenso en el uso de POCUS en RCP}

En 2010, la American Society of Echocardiography (ASE) y el American College of Emergency Physicians (ACEP) establecieron un consenso sobre las aplicaciones de ecocardiografía en el servicio de urgencias. El objetivo de la ecocardiografía focalizada (FoCUS) en el PCR es: 1) diferenciar el ritmo cardíaco organizado de la asistolia, la actividad eléctrica sin pulso (AESP) verdadera y la pseudo-AESP; 2) encontrar causas reversibles de PCR y 3 ) realizar procedimientos guiados por ultrasonido durante la RCP y en RCE[9]. La European Society of Cardiology (ESC) declaró que la ecocardiografía podría mejorar el diagnóstico y cambiar la conducta clínica de la atención en pacientes con paro cardíaco[10]. Las guías europeas de reanimación también potenciaron las recomendaciones e incorporaron el ultrasonido en el soporte vital avanzado. Finalmente, en 2017, la ACEP aprobó las pautas sobre el uso de la ecocardiografía transesofágica (ETE) en el paro cardíaco[11] (Figura 1).

Se ha demostrado además que la palpación manual de pulso tiene una sensibilidad de 55\% para diagnóstico de PCR, lo cual lleva a un retardo en el inicio de las maniobras de compresión torácicas[12].

\section{PoCUS en PCR}

El ultrasonido no debe retrasar las compresiones torácicas. Cuando un paciente llega al servicio de ur- 
gencias en paro cardíaco, el objetivo principal es lograr y mantener una RCP de alta calidad. En este sentido el uso de ultrasonido debe introducirse sólo cuando ya se ha establecido una reanimación adecuada. Su implementación tampoco debe retrasarse demasiado hacia el final de la RCP (sobretodo en un ritmo no desfibrilable), considerando que la detección y el manejo precoz de las causas potencialmente reversibles de paro cardiaco otorgan mayores posibilidades de supervivencia. La prioridad durante el procedimiento debe mantenerse en las compresiones torácicas de calidad y la utilización de ecocardiografía solo debe iniciarse si no interrumpe este procedimiento[10].

Ha sido descrito en la literatura la implicancia del FoCUS en PCR en el retraso de maniobras de reanimación y compresiones torácicas. Algunos estudios han logrado demostrar que el uso de la ecografía aumenta el tiempo sin compresión durante los chequeos de pulso. Entre estos se encontraba un estudio de cohorte prospectivo realizado por Huis et al., en el que se observó mediante cámaras las interrupciones en las maniobras de reanimación en un servicio de urgencias[13]. Se encontró que la duración media de las comprobaciones del pulso y la interrupción de las compresiones torácicas con PoCUS fue de 21,0 s, en comparación con una duración media sin PoCUS de 13,0 s. Por lo tanto, el estudio demostró que el uso de PoCUS aumentó significativamente la duración de la verificación del pulso en 8,4 s.

Por otra parte, algunos investigadores han evidenciado que el uso de PoCUS durante el chequeo de pulso no resulta en una prolongación significativa del tiempo. Por ejemplo, un estudio realizado por $\mathrm{Ha}-$ yhurst et al., encontró que las imágenes se obtuvieron en menos de 10 segundos en el $90 \%$ de los casos[14], mientras que Gaspari et al. informaron que las imágenes de FoCUS registradas durante la RCP tenían una duración promedio de 4,5 segundos[15]. El examen debe ajustarse al contexto del paciente y utilizar metodologías audiovisuales como la grabación de imágenes para optimizar la revisión diagnóstica posterior sin desmedro de las maniobras de RCP. Esta información recabada debe estar a disposición inmediata del líder de la reanimación para guiar el tratamiento. Finalmente, pese a las diferencias en los tiempos de obtención de imágenes, la literatura es inflexible en recalcar que no se debe retrasar el inicio de las compresiones torácicas en pos de realizar una evaluación ecográfica coadyuvante.

\section{Protocolos de FoCUS}

En la última década se han propuesto distintos protocolos estructurados de manejo ecocardiográfico focalizado, sobretodo en el contexto de resucitación en PCR, donde el principal objetivo es identificar o descartar causas reversibles de PCR en ritmos no desfibrilables[16]. Los protocolos descritos forman parte del nivel intermedio de entrenamiento. Aún no se describe un protocolo de FoCUS universal y la literatura no destaca uno por sobre otro.

El examen FoCUS busca responder rápidamente preguntas acotadas al evaluar sistemática y globalmente ventrículos, pericardio, válvulas, vena cava inferior y en algunas instancias pulmón y pleura[17]. Tambien juega un rol importante en el manejo de las causas reversibles de shock que generalmente no están claras durante la reanimación y se pueden identificar fácilmente mediante el uso de ultrasonido, como anomalías en el movimiento de la pared en pacientes con infarto agudo de miocardio. El ultrasonido también juega un papel clave después de que se ha logrado RCE pudiendo guiar el manejo de líquidos durante este periodo al escanear la vena cava inferior y reevaluar los pulmones para el desarrollo de edema pulmonar.

Dentro de los protocolos propuestos en los últimos años destacan: FATE (Focus Assessed Transthoracic Echo), FEEL (Focused Echocardiography in Emergency Life Support), FEER (Focused Echocardiographic Evaluation in Resuscitation), CAUSE (Cardiac Arrest Ultra-Sound Exam), PEA (Paraesternal - Apical - Abdomen) y SESAME (Sequential Emergency Sonography Assessing Mechanism or origin of severe shock of indistinct cause)

\section{Protocolo FEER}

El protocolo FEER fue introducido por Breitkreutz et al., como el primer algoritmo que incorpora la ecografía cardíaca en la RCP[18]. Esta metodología FEER se recomienda implementar después de 5 ciclos de RCP de alta calidad. FEER se realiza sólo durante el chequeo de pulso de 10 segundos y posee un orden estructurado, cambiando de ventana después de cada ciclo (Tabla 1).

\section{Protocolo CAUSE}

Por otra parte, el protocolo CAUSE sugiere la ventana subxifoidea para mantener la monitorización continua durante toda la reanimación o utilizar la ventana de mayor preferencia o experiencia del operador, cambiándola cada 3 segundos si no se logra una imagen satisfactoria[19]. Hernández et al., desarrollaron el protocolo CAUSE para identificar 4 causas poten- 


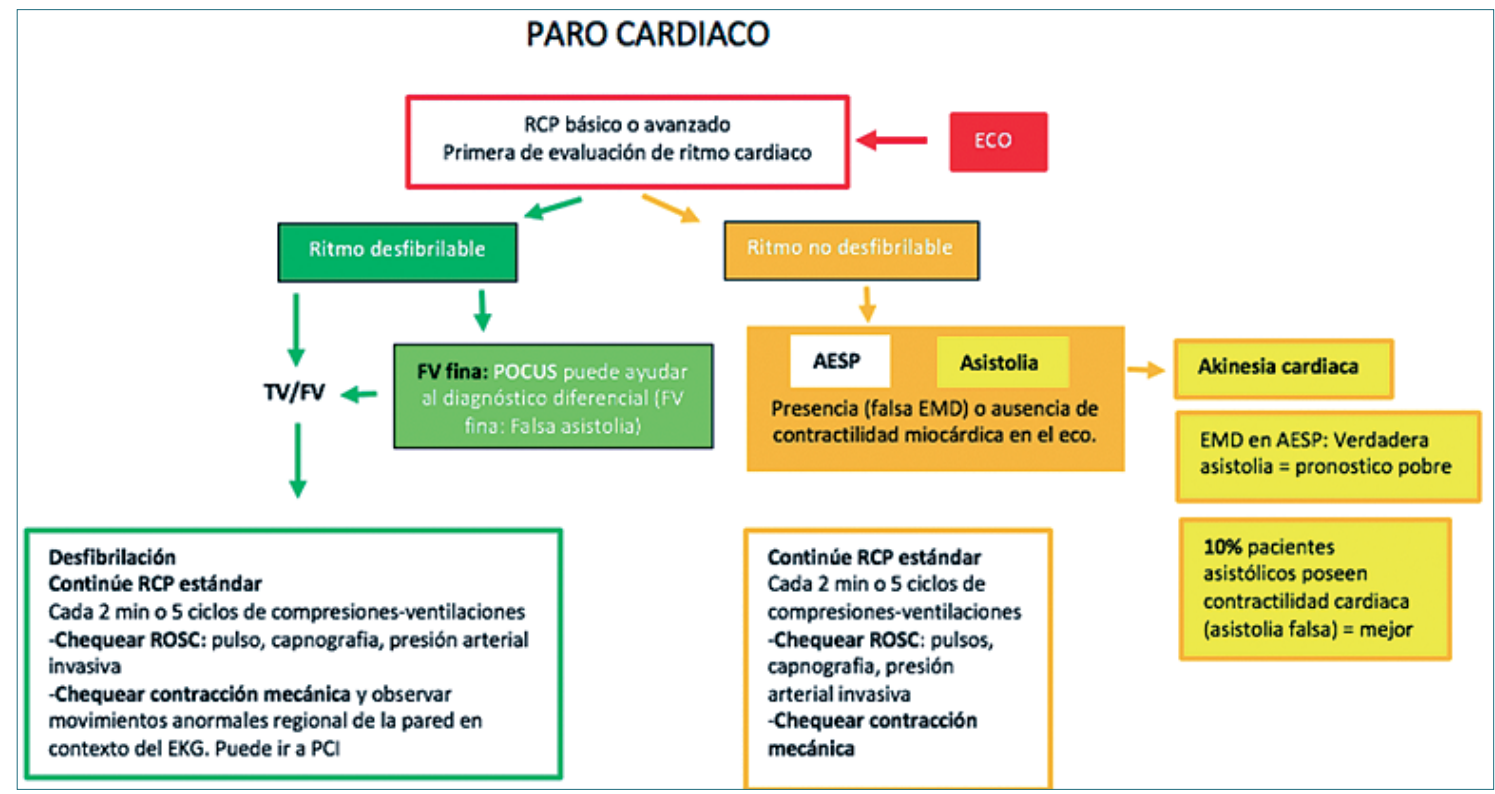

Figura 1. Algoritmo para la integración de la ecografía point of care (POCUS) en resucitación cardiopulmonar (RCP). TV: taquicardia ventricular; FV: fibrilación ventricular; ROSC: retorno a la circulación espontanea; EKG: electrocardiograma; PCI: intervención coronaria percutánea; AESP: actividad eléctrica sin pulso; EMD: disociación electromecánica. Adaptado de Blanco P, Martínez Buendía C. Point-of-care ultrasound in cardiopulmonary resuscitation: a concise review. Journal of Ultrasound. 2017;20(3):193-198.

\section{Tabla 1.}

\begin{tabular}{|c|c|}
\hline Fase & Elementos de commando \\
\hline \multirow{5}{*}{$\begin{array}{l}\text { 1. RCP de alta calidad, } \\
\text { preparación informa- } \\
\text { ción al equipo }\end{array}$} & $\begin{array}{l}\text { 1. Realizar ACLS o BLS correcto e inmediato según guías de la AHA/ERC/ILCOR por lo menos por } \\
5 \text { ciclos de compresión/ventilación }\end{array}$ \\
\hline & 2. Informar al equipo de RCP: "Estoy preparando un eoccardiograma" \\
\hline & 3. Preparar el ecógrafo portatil y probarlo. \\
\hline & 4. Acomodar la situación: Mejor posición del paciente, remoción de ropa, estar listo para empezar \\
\hline & $\begin{array}{l}\text { 5. Informar al equipo de RCP que inicie conteo de } 10 \text { segundos para tomar el pulso simultánea- } \\
\text { mente. }\end{array}$ \\
\hline \multirow{3}{*}{$\begin{array}{l}\text { 2. Ejecución, obtención } \\
\text { del ecocardigrama }\end{array}$} & 6. Ordenar: "Interrumpir RCP al final de este ciclo para hacer el ecocardiograma \\
\hline & 7. Posicionar el transductor gentilmente en la región subxifoidea durante las compresiones" \\
\hline & $\begin{array}{l}\text { 8. Realizar un ecocardiograma subcostal (eje largo) tan rápido como sea posible. Si o se identi- } \\
\text { fica el corazón en } 3 \text { segundos, para la interrupción y repetir } 5 \text { ciclos después en otra ventana o } \\
\text { abordaje paraesternal }\end{array}$ \\
\hline 3. Reinicio RCP & 9. Ordenar a los 9 segundssegundos como máximo: "continue RCP y controlar" \\
\hline $\begin{array}{l}\text { 4. Interpretación y con- } \\
\text { secuencias }\end{array}$ & $\begin{array}{l}\text { 10. Comunicar (después de la continuación de compresiones) los hallazgos al equipo RCP (mo- } \\
\text { vilidad pared, compresión cardiaca efectiva, akinesia, derrame pericardico masivo, sospecha de } \\
\text { embolismo pulmonar, hipovolemia) y explicar las cosecuencias }\end{array}$ \\
\hline
\end{tabular}

Evaluación ecocardiográfica focalizada en resucitación (FEER); manejo del examen en 10 pasos; RCP: reanimación cardiopulmonar; BLS: soporte vital básico; ACLS: soporte vital avanzado; AHA: American Heart Association; ERC: European Resuscitation Council; ILCOR: International Liason Commitee on Resuscitation. Adaptado de Blanco P, Martínez Buendía C. Point-of-care ultrasound in cardiopulmonary resuscitation: a concise review. Journal of Ultrasound. 2017;20(3):193-198. 


\section{Tabla 2. Hallazgos ecocardiográficos potenciales durante reanimación cardiopulmonar}

\begin{tabular}{|c|c|}
\hline Hallazgos ecocardiográficos posibles asociado a clínica & Diagnóstico \\
\hline Movimiento pared miocárdica & Presencia de circulación \\
\hline Ausencia de movimientos cardiacos & Parada cardiaca \\
\hline Función ventricular limitada severa & Insuficiencia miocárdica \\
\hline Dissincronía ventricular izquierda & Insuficiencia miocárdica \\
\hline Movimiento pared, ausencia de pulso y ritmo regular & Pseudo - AESP \\
\hline Aquinesia, ausencia de pulso y ritmo regular & AESP verdadera \\
\hline $\begin{array}{l}\text { Pared ventricular izquierda hipercontráctil, contacto trabécu- } \\
\text { las, hipotensión y taquicardia }\end{array}$ & Hipovolemia \\
\hline $\begin{array}{l}\text { Pared ventricular izquierda hipercontráctil asincrónico, con- } \\
\text { tacto trabéculas, hipotensión y taquicardia }\end{array}$ & $\begin{array}{l}\text { Descartar Takotsubo } \\
\text { Descartar SAM }\end{array}$ \\
\hline Dilatación de cavidades derechas, signo "D" & Embolia pulmonar \\
\hline Derrame pericárdico, colapso VD en diástole, VCI no colapsa & Taponamiento pericárdico \\
\hline Hallazgos no concluyentes & Sin diagnóstico \\
\hline
\end{tabular}

Adaptado de Breitkreutz R, Price S, Steiger H, Seeger F, Ilper H, Ackermann H, et al. Focused echocardiographic evaluation in life support and peri-resuscitation of emergency patients: A prospective trial. Resuscitation. 2010;81(11):1527-1533.

cialmente reversibles de PCR: un ventrículo derecho dilatado en la embolia pulmonar, líquido alrededor del corazón en taponamiento pericárdico, ventrículos colapsados en hipovolemia y ausencia de deslizamiento pulmonar en neumotórax a tensión. Los autores también han sugerido puntos de vista adicionales que se pueden obtener en la hipovolemia, como la vena cava inferior para confirmar un "estanque vacío", así como la aorta abdominal para evaluar el aneurisma como causa de hipovolemia (Figura 2 y Tabla 2).

Las pautas de la ASE y el ACEP recomiendan el uso de PoCUS solo en la AESP o asistolia y desalientan su uso en ritmo desfibrilable[20]. Su justificación es racional, ya que la identificación de la fibrilación ventricular (FV) o la taquicardia ventricular sin pulso (TVSP) debe ir seguida de un shock inmediato y la reanudación de las compresiones torácicas. Es poco probable que la detección de patologías como anomalías en el movimiento de la pared o miocardiopatía hipertrófica afecte el tratamiento durante la RCP, pero debe identificarse después del RCE.

\section{Ventanas ecográficas}

\section{Ecocardiograma transtorácico}

Se estima que su uso en el contexto intraoperatorio de PCR puede cambiar el manejo durante la reanimación entre 30\% - 70\% de los casos[21]. Se descri- ben cuatro ventanas clásicas: 1) paraesternal largo; 2) paraesternal corto; 3) apical de 4 cámaras y 4) subxifoídeo. La literatura muestra un mayor rendimiento y una curva de aprendizaje menor para las ventanas paraesternal y subxifoídea que para la ventana apical de cuatro cámaras, por lo que su evaluación tiende a depender del perfeccionamiento continuo del operador[16] (Figura 3).

\section{Ecocardiograma transesofágico}

Se evidenció una mejoría del impacto diagnóstico en $78 \%$ casos y terapéutico en $67 \%$, incluyendo mejoría en la calidad, tiempo y ubicaciones de las compresiones torácicas hasta 43\%[22]. Las principales contribuciones fueron la evaluación continua de las compresiones torácicas, exclusión de causa cardiaca (56\%), detección de insuficiencia ventricular izquierda $(15 \%)$, evidencia de hipovolemia (13\%) y alteración de la motilidad de la pared miocárdica (6\%). En los casos de hipovolemia, mejoró la guía terapéutica discriminando el impacto ecográfico de la fluidoterapia vs el uso de agentes vasoactivos[23].

Su uso en PCR se ve limitado principalmente por la habilidad del operador para insertar la sonda, la descompresión gástrica previa, el factor humano y la disponibilidad de un equipo ecográfico compatible. La complicación más peligrosa es la perforación esofágica con $0,03 \%$ de incidencia[22].

Las ventanas de mayor rendimiento incluyen: 1) 


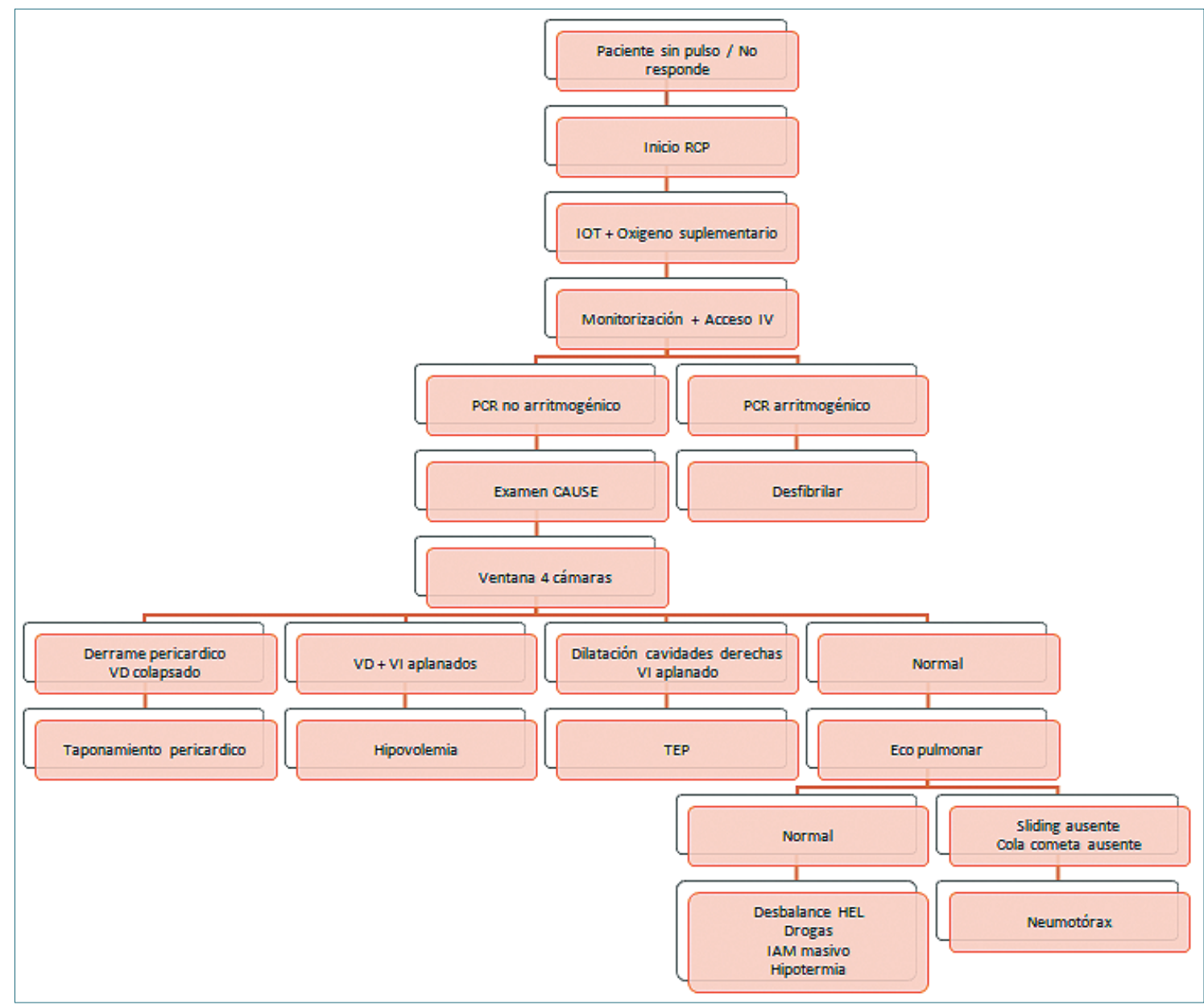

Figura 2. Diagrama de flujo demostrando el uso del protocolo CAUSE en pacientes con PCR. Adaptado de Blanco P, Martínez Buendía C. Point-of-care ultrasound in cardiopulmonary resuscitation: a concise review. Journal of Ultrasound. 2017;20(3):193198.

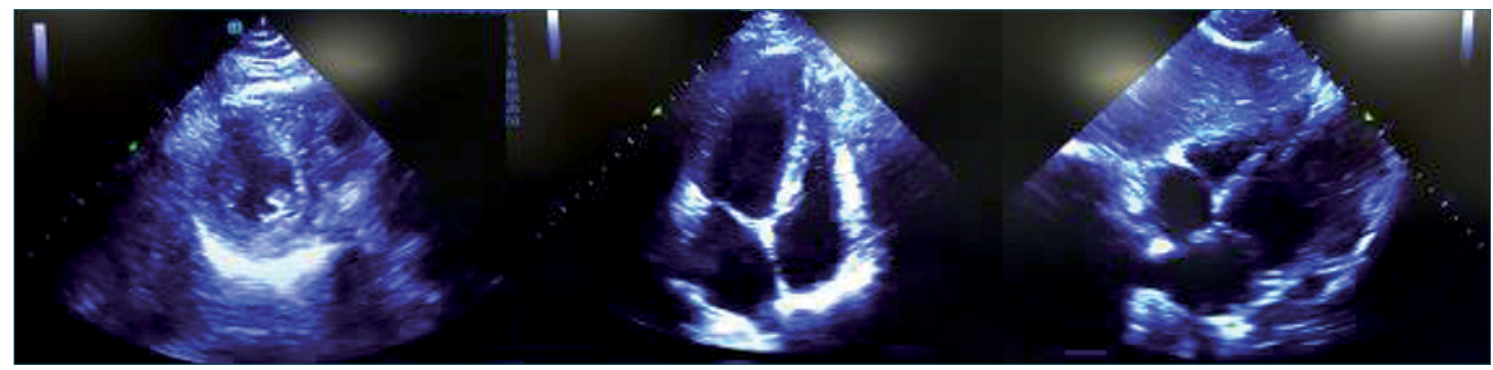

Figura 3. Imágenes ecográficas del corazón. A) Visión paraesternal eje corto; B) Visión apical de 4 cámaras; C) Visión subxifoidea. 
medio esofágica cuatro cámaras; 2) ventana transgástrica eje corto; 3) ventana medio esofágica eje largo y ventana bicaval.

\section{Escenarios clínicos}

\section{Asistolia}

Levitov et al., sugieren el uso del ecocardiograma en asistolia para guiar y definir si se continua con las maniobras de reanimación y terapéuticas posteriores[21]. Esto incluye el diagnóstico certero de asistolia al evaluar efectivamente si existe o no movimientos cardiacos espontáneos presentes al momento de la evaluación. Diversos estudios que utilizaron POCUS evidenciaron la presencia de MCE entre 10\%-35\% lo cual cambiaría el outcome[18],[20]. El ecocardiograma con diagnóstico de asistolia en ausencia de movimientos cardiacos posee un factor pronóstico cercano al $100 \%$ de mortalidad. Esto lleva a considerar la posibilidad de la suspensión de las maniobras de reanimación si no existe respuesta positiva a la RCP inicial.

\section{AESP}

Actualmente, la AESP implica un desafío diagnóstico y la habilidad para certificarla mediante la palpación de pulso de la arteria carótida ha sido cuestionado, ya que presentaría una sensibilidad entre $45 \%$ a $55 \%$ para detección de pulso manual[12]. Respecto a la AESP se sugiere el uso de FoCUS para el correcto diagnóstico de dicha entidad, diferenciándola de una pseudo-AESP e identificar sus causas potenciales[21]. Al mismo tiempo la ecografía permite identificar las causas reversibles, realizando una hipótesis pronostica basado en la presencia de movimientos cardiacos sincrónicos (Tabla 3).

En pacientes con pseudo AESP la ecografía identifica una función ventricular izquierda reducida en $59 \%$, taponamiento pericárdico en 9,8\% y ventrículo derecho significativamente dilatado en $7,8 \%$. La hipovolemia evaluada por un volumen diastólico final del ventrículo izquierdo bajo o por medición del diámetro de la vena cava inferior se detectó en 3,9\% de los casos[24]. Como factor pronóstico es relevante diferenciar la AESP verdadera, de la pseudo-AESP; y a partir de esta última la presencia de movimientos cardiacos sincrónicos o asincrónicos.

\section{Pseudo - AESP con actividad cardiaca sincrónica}

Se definió AESP con actividad eléctrica sincrónica a aquella que evidenciaba cambios ecográficos en las dimensiones ventriculares al momento de contraerse. Pacientes en AESP con actividad cardiaca sincrónica que recibieron intervenciones clásicas del protocolo ACLS obtenían mejor sobrevida a la admisión hospitalaria (37,7\% vs 17,9\%) que aquellos con actividad cardiaca asincrónica, lo cual podría extrapolarse al contexto intrahospitalario[20].

Los pacientes que recibieron agentes adrenérgicos continuos (epinefrina, dopamina, noradrenalina) previo a al retorno a la circulación espontánea (RCE) poseían una mayor sobrevida a la admisión hospitalaria $(45,5 \%$ vs $0 \%)$ y mayor RCE $(90,9 \%$ vs $47,1 \%)$ comparados con aquellos con actividad cardiaca asincrónica. Por tanto, se establece una relación de sobrevida en pacientes en este escenario y el uso de fármacos adrenérgicos de elección[24].

\section{Pseudo- AESP con actividad cardiaca asincrónica}

Se definió AESP con actividad asincrónica a aquellos movimientos caóticos sin evidencia de contracción ordenada y sin cambios de la precarga ventricular. En este escenario, con maniobras de reanimación estándar se lograba una sobrevida a la admisión hospitalaria de 17,9\%. Además, se evaluó el bajo impacto terapéutico de los agentes adrenérgicos en este ritmo con sobrevida al alta de solo 4,5\%[20].

\section{Evaluación AESP según ECG y PoCUS}

Las causas descartables para AESP y asistolia presentadas en los algoritmos del ACLS (5H's y 5'Ts) pierden su secuencia lógica de abordaje durante las maniobras de reanimación; no permitiendo un algoritmo de trabajo enfocado a descartar la principal causa etiológica atribuible a la AESP de manera ordenada.

Actualmente, se ha propuesto un algoritmo que utiliza la evaluación conjunta del electrocardiograma (ECG) y ecocardiograma focalizado para tratar con mayor asertividad un paro por esta causa. El primer paso es determinar el ancho del QRS, discriminando un QRS estrecho (<120 ms) versus ancho (> 120 ms[25] (Figura 4).

\section{QRS estrecho}

Los complejos QRS estrechos suelen asociarse con patologías mecánicas como la obstrucción al flujo de entrada o salida del ventrículo derecho, que incluyen taponamiento cardíaco, neumotórax a tensión, hiperinflación mecánica, embolismo pulmonar o IAM mecánico. Un ventrículo derecho (VD) colapsado sugiere 
obstrucción de entrada mientras que un VD dilatado sugiere obstrucción de salida. La terapia mecánica especifica (liberación, drenaje, trombolisis, etc.) debe considerarse como primera aproximación[25].

\section{QRS ancho}

Los complejos QRS anchos se asocian principalmente con alteraciones hidroelectrolíticas y de canales iónicos como la toxicidad por bloqueadores del canal de sodio (anestésicos locales), hiperpotasemia grave, ritmo agonal o infarto agudo de miocardio con falla de bomba. En estas etiologías, FoCUS a menudo mostrará una hipoquinesia global y segmentaria del ventrículo izquierdo o AESP verdadera. La terapia farmacológica específica debe considerase como primera aproximación versus una resolución mecánica[26].

\section{Valor pronóstico de PoCUS en PCR}

Con la disponibilidad cada vez mayor de dispositivos de ultrasonido, creemos que probablemente habrá una mayor comodidad y habilidad del médico con el uso de PoCUS en el servicio de urgencias y la atención crítica.

Una revisión sistemática publicada el 2020 por Kedan et al., analizó estudios donde se evaluaba el movimiento cardíaco ecográfico como un predictor de mortalidad después de la reanimación cardíaca[27]. En

\begin{tabular}{|c|c|}
\hline \multicolumn{2}{|c|}{ Causas frecuentes de AESP ("Hs y Ts") } \\
\hline Hipovolemia & Toxinas \\
\hline Hipoxia & Taponamiento \\
\hline Hidrogeniones (acidosis) & $\begin{array}{l}\text { Tensión (Neumotórax a ten- } \\
\text { sión) }\end{array}$ \\
\hline Hiperkalemia & Trombosis coronaria \\
\hline Hipokalemia & TEP \\
\hline Hipotermia & Trauma* \\
\hline Hipoglicemia* & \\
\hline
\end{tabular}

*Hipoglicemia y trauma fueron removidas de las guías más recientes de ACLS.

14 estudios se evidenció una correlación estadísticamente significativa entre la presencia de movimiento cardíaco en la ecografía y la supervivencia a corto plazo. El $60,7 \%$ de los pacientes que tenían movimiento cardíaco a la ecografía presentaron un resultado de reanimación positivo. Por el contrario, el $12,4 \%$ de los pacientes sin movimiento cardíaco espontáneo presentaron un resultado positivo. Específicamente, de los pacientes con AESP como ritmo inicial, el 58,8\% de los que presentaron MCE cumplieron con los criterios para un resultado positivo de reanimación. Por

\section{AESP}
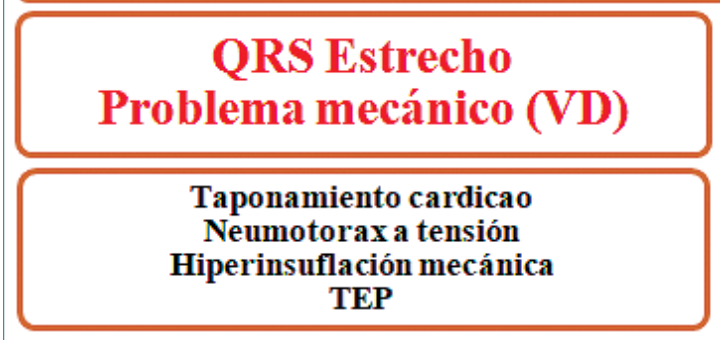

\section{IAM agudo Ruptura miocardica}

\section{Ecocardio: VI hiperdinamico Pseudo AESP}
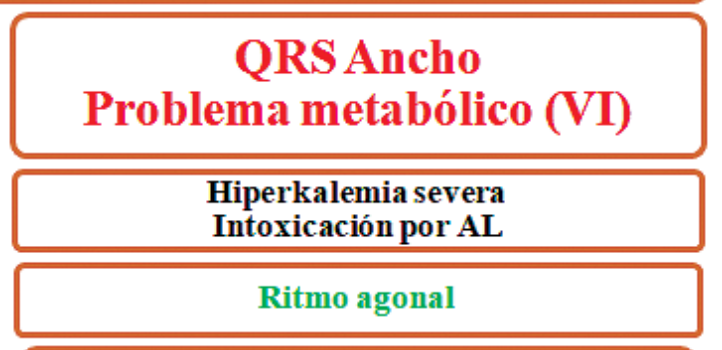

IAM agudo Insuficiencoa miocardica

\section{VI hipokinetico/akinesia Pseudo - AESP}

Figura 4. Nueva clasificación y aproximación a AESP basada en su manifestación ECG inicial y evaluación ecocardiografica. 
el contrario, el 13,8\% (26/188) de los pacientes sin movimiento cardíaco en POCUS cumplieron los criterios para un resultado positivo de RCE, supervivencia al ingreso hospitalario o supervivencia de $24 \mathrm{~h}$. Usando RCE como el resultado primario, los resultados de todos los estudios se agruparon para calcular la probabilidad de RCE en presencia de MCE. El odds ratio global agrupado para RCE en presencia de movimiento cardíaco durante la RCP fue de 12,4.

Si bien estos resultados sugieren que POCUS proporciona información adicional de diagnóstico y pronóstico en el manejo del paro cardíaco, con el conocimiento actual sobre POCUS en el contexto del paro cardíaco, creemos que es de vital importancia que las imágenes en el punto de atención no interfieran con el estándar de soporte vital cardíaco avanzado, considerando además que la ecocardiografía también tiene un aporte tras una RCP exitosa, e incluso como control por PCR a las 24 y/o $48 \mathrm{~h}$ del evento.

\section{PoCUS post PCR}

La utilidad de la ecocardiografía se extiende más allá de su aplicación durante la reanimación. Las anormalidades ecocardiográficas son comunes después de la reanimación por paro cardíaco, sin embargo, un estudio prospectivo por Jentzer et al., estableció que los parámetros ecocardiográficos a las $24 \mathrm{~h}$ post reanimación no se asociaron con la mortalidad intrahospitalaria y la necesidad de vasopresores ni la gravedad de la falla orgánica se asociaron con los marcadores ecocardiográficos de función sistólica[28].

Sin embargo, posteriormente un estudio retrospectivo por el mismo grupo observó que se producen cambios significativos en la función sistólica y los parámetros hemodinámicos en ETT seriados después de PCR extrahospitalario[29]. El ETT inicial se realizó una mediana de 10.4 horas después del ingreso y la repetición de TTE se realizó $5,7 \pm 4,1$ días después. Entre exámenes, hubo aumentos significativos en la fracción de eyección del ventrículo izquierdo (32\% a $43 \%$ ), gasto cardíaco y volumen sistólico. La función sistólica y los parámetros hemodinámicos en TTE inicial no se asociaron con la mortalidad de seguimiento. Pero los pacientes que murieron durante el seguimiento (27\%) tuvieron aumentos menores en la FEVI y los parámetros hemodinámicos derivados del gasto cardíaco que los sobrevivientes a largo plazo, enfatizando que el grado de recuperación de la disfunción miocárdica posterior al paro puede ser más importante que su gravedad inicial.

Finalmente, los estudios más recientes han establecido que la disfunción diastólica en ETT es un predictor independiente de mortalidad después de un PCR extrahospitalario, pero no la disfunción sistólica y los parámetros hemodinámicos medidos por ecocardiografía[30]. Esto refleja un uso novedoso de Doppler transtorácico para predecir resultados después de una RCP.

En el contexto de PCR intrahospitalaria el nivel de evidencia es menor. Sin embargo, se ha establecido que solamente la realización de ecocardiografía 2D dentro de las $24 \mathrm{~h}$ posteriores a RCE se asoció con mejores resultados de sobrevida intrahospitalaria para pacientes que se sometieron a RCP por un PCR intrahospitalaria secundario a una etiología cardíaca. Por lo tanto, la ecocardiografía 2D se puede realizar dentro de las $24 \mathrm{~h}$ posteriores a RCE en pacientes que experimentan PCR intrahospitalario para permitir un mejor tratamiento y mejorar la sobrevida[31].

\section{Limitaciones}

Dentro de las limitaciones en estos protocolos se incluyen el entrenamiento del personal operador y el nivel de formación académica. Además, el médico ecografista deberá adaptarse a posiciones forzadas del paciente dependiendo del contexto clínico donde ocurra el PCR y se produzca la reanimación, disminuyendo el rendimiento de las ventanas ecográficas disponibles y obteniendo imágenes de mala calidad, implicando un desafío diagnóstico que no debe retrasar el masaje cardiaco o las maniobras de reanimación.

Desde el punto de vista técnico y económico la disponibilidad de equipamiento, la calidad imagenológica del equipo y su portabilidad son factores que pueden afectar el examen. El factor humano persiste como la variable relevante más importante. Los recursos humanos derivados de una reanimación cardiovascular avanzada y la coordinación logística y limitación de tareas asignadas para disminuir las interrupciones durante la RCP son los elementos que fallan habitualmente.

\section{Discusión}

Actualmente, el uso de la ecografía focalizada se posiciona como una herramienta segura, simple de implementar y efectiva a la hora de diagnosticar en el contexto de urgencia. Cuando se utiliza en cuidados críticos cardiacos, el FoCUS permite responder rápidamente preguntas específicas e interpretarlas en un breve período de tiempo. En situaciones críticas como PCR se ha evaluado un rendimiento favorable en la aplicación de protocolos complementarios de 
reanimación cardiovascular, llegando a suplir el vacío derivado de la incertidumbre diagnóstica en etiologías potencialmente reversibles asociadas a ritmos no desfibrilables. El ecocardiograma ha probado ser un examen altamente sensible y específico para el diagnóstico de causas reversibles como taponamiento cardiaco, hipovolemia y embolismo pulmonar.

En conjunto con el electrocardiograma es capaz de guiar la terapia farmacológica basado en la probabilidad de alteraciones hidroelectrolíticas, metabólicas y/o mecánicas que gatillaron el PCR en primera instancia. Su uso durante la temporalidad del PCR idealmente debe ser definido en concordancia con los protocolos en los cuales el operador ha sido entrenado; proponiéndose su utilización al inicio y al final del RCP para reconocimiento de ritmo; o durante todo el proceso de reanimación para favorecer la guía dinámica de tratamiento. Este último uso pareciera ser el que mejor rendimiento presentaría, ya que se observaría la mejoría evolutiva del paciente con los tratamientos instaurados.

En el contexto de los cuidados post paro cardiorrespiratorio está definida su utilidad para determinar la función cardiaca global y según esto guiar el tratamiento posterior. Es interesante observar cómo la sola realización de este examen mejora la sobrevida de los pacientes cuando su PCR fue de origen cardiaco, enfatizando la importancia de una evaluación exhaustiva. Llama la atención como los parámetros hemodinámicos ecocardiograficos inmediatos no parecieran permitirnos establecer un pronostico a largo plazo en el grupo de pacientes con RCE, pero sí la evaluación seriada y la mejoría de la función sistólica del VI dan cuenta de la importancia del adecuado seguimiento y manejo de estos pacientes guiándose por técnicas de ultrasonido.

\section{Conclusiones}

En resumen, el uso de FoCUS es una herramienta coadyuvante costo-efectiva positiva para el manejo de PCR en el ambiente hospitalario. La literatura avala su valor como examen pronóstico de sobrevida negativo ante ausencia de movimientos cardiacos espontáneos, asistolia y AESP verdadera. Además, incluye un factor pronóstico positivo de RCE y sobrevida hospitalaria en pseudo-AESP. El ecocardiograma focalizado permitiría el diagnóstico acotado y precoz de causas reversibles de PCR en ritmos no desfibrilables $y$, subsecuentemente guiar y evaluar las medidas terapéuticas empleadas durante la RCP.

\section{Referencias}

1. Hussein, L., Rehman, M.A., Sajid, R. et al. Bedside ultrasound in cardiac standstill: a clinical review. Ultrasound J 2019; 11, 35 https://doi.org/10.1186/s13089019-0150-7

2. Gaspari R, Weekes A, Adhikari $S$ et al. Emergency department point-of-care ultrasound in out-of-hospital and in-ED cardiac arrest. Resuscitation 2016; 109:33-39 https:// doi.org/10.1016/j.resuscitation.2016.09.018

3. Bailey E, Wydro G, Cone D. Termination of resuscitation in the prehospital setting for adult patients suffering nontraumatic cardiac arrest. Prehosp Emerg Care 2000; 4:190-195 https:// doi..1080/10903120090941498
4. Herlitz J. Factors associated with survival to hospital discharge among patients hospitalised alive after out of hospital cardiac arrest: change in outcome over 20 years in the community of Goteborg, Sweden. Heart 2003; 89:25-30 https://doi. org/10.1136/heart.89.1.25

5. Herlitz J. Can we define patients with no chance of survival after out-of-hospital cardiac arrest? Heart 2004; 90:11141118. https://doi.org/10.1136/ hrt.2003.029348

6. Bobrow B, Zuercher M, Ewy G et al Gasping during cardiac arrest in humans is frequent and associated with improved survival. Circulation 2008; 118:25502554. https://doi.org/10.1161/ CIRCULATIONAHA. 108.799940

7. Eckstein M, Hatch L, Malleck
J et al. End-tidal $\mathrm{CO} 2$ as a predictor of survival in out-ofhospital cardiac arrest. Prehosp Disas Med 2011; 26:148150. https://doi.org/10.1017/ S1049023X11006376

8. Clements F, de Bruijn N, Kisslo J. Transesophageal echocardiographic observations in a patient undergoing closedchest massage. Anesthesiology 1986; 64:826-828. https:// doi.org/10.1097/00000542198606000-00030

9. Labovitz A, Noble V, Bierig M et al. Focused cardiac ultrasound in the emergent setting: a Consensus Statement of the American Society of Echocardiography and American College of Emergency Physicians. J Am Soc Echocardiogr 2010; 23:12251230. https://doi.org/10.1016/j. 
echo.2010.10.005

10. Maconochie I, Bingham R, Eich $C$ et al European Resuscitation Council Guidelines for Resuscitation 2015. Resuscitation 2015; 95:223-248. https:// doi.org/10.1016/j.resuscitation.2015.07.028

11 Guidelines for the use of transesophageal echocardiography (TEE) in the ED for cardiac arrest. Ann Emerg Med (2017) 70:442445. https://doi.org/10.1016/j. annemergmed.2017.06.033

12. Chenkin J, Atzema C. Contemporary Application of Pointof-Care Echocardiography in the Emergency Department. Canadian Journal of Cardiology. 2018;34(2):109-116. https://doi. org/10.1016/j.cjca.2017.08.018

13. Huis in 't Veld M, Allison M, Bostick D et al. Ultrasound use during cardiopulmonary resuscitation is associated with delays in chest compressions. Resuscitation 2017; 119:95-98. https://doi.org/10.1016/j.resuscitation.2017.07.021

14. Hayhurst $C$, Lebus $C$, Atkinson $P$ et al (2010) An evaluation of echo in life support (ELS): is it feasible? What does it add? Emerg Med J 28:119-121. https://doi. org/10.1136/emj.2009.084202

15. Gaspari R, Weekes A, Adhikari $S$, Noble V, Nomura J, Theodoro $D$ et al. A retrospective study of pulseless electrical activity, bedside ultrasound identifies interventions during resuscitation associated with improved survival to hospital admission. A REASON Study. Resuscitation. 2017; 120:103-107. https:// doi.org/10.1016/j.resuscitation.2017.09.008

16. Spencer K, Kimura B, Korcarz C, Pellikka P, Rahko P, Siegel R. Focused Cardiac Ultrasound: Recommendations from the American Society of Echocardiography. Journal of the American
Society of Echocardiography. 2013; 26(6):567-58. https://doi. org/10.1016/j.echo.2013.04.001

17. Tsou P, Kurbedin J, Chen $Y$, Chou $E$, Lee $M$, Lee $M$ et al. Accuracy of point-of-care focused echocardiography in predicting outcome of resuscitation in cardiac arrest patients: A systematic review and meta-analysis. Resuscitation. 2017; 114:92-99. https://doi.org/10.1016/j.resuscitation.2017.02.021

18. Breitkreutz R, Walcher F, Seeger $F$. Focused echocardiographic evaluation in resuscitation management: Concept of an advanced life support-conformed algorithm. Critical Care Medicine. 2007; 35: S150-S161. https://doi.org/10.1097/01. CCM.0000260626.23848.FC

19. Hernández $C$, Shuler K, Hannan $H$, Sonyika C, Likourezos A, Marshall J. C.A.U.S.E.: Cardiac arrest ultra-sound exam-A better approach to managing patients in primary non-arrhythmogenic cardiac arrest. Resuscitation. 2008; 76(2):198-206. https:// doi.org/10.1016/j.resuscitation.2007.06.033

20. Blanco P, Martínez Buendía C. Point-of-care ultrasound in cardiopulmonary resuscitation: a concise review. Journal of UItrasound. 2017; 20(3):193-198. https://doi.org/10.1007/s40477017-0256-3

21. Levitov $A$, Frankel $H$, Blaivas $M$, Kirkpatrick A, Su E, Evans D et al. Guidelines for the Appropriate Use of Bedside General and Cardiac Ultrasonography in the Evaluation of Critically III Patients-Part II. Critical Care Medicine. 2016; 44(6):12061227. https://doi.org/10.1097/ CCM.0000000000001847

22. Arntfield R, Pace J, Hewak M, Thompson D. Focused Transesophageal Echocardiography by Emergency Physicians is
Feasible and Clinically Influential: Observational Results from a Novel Ultrasound Program. The Journal of Emergency Medicine. 2016; 50(2):286-294. https:// doi.org/10.1016/j.jemermed.2015.09.018

23. Blaivas M. Transesophageal echocardiography during cardiopulmonary arrest in the emergency department. Resuscitation. 2008; 78(2):135-140. https:// doi.org/10.1016/j.resuscitation.2008.02.021

24. Breitkreutz $R$, Price $S$, Steiger $H$, Seeger $F$, Ilper $H$, Ackermann $H$ et al. Focused echocardiographic evaluation in life support and peri-resuscitation of emergency patients: A prospective trial. Resuscitation. 2010; 81(11):15271533. https://doi.org/10.1016/j. resuscitation.2010.07.013

25. Atkinson P R, Keyes A W, O'donnell K, et al. (November 23, 2018) Do Electrocardiogram Rhythm Findings Predict Cardiac Activity During a Cardiac Arrest? A Study from the Sonography in Cardiac Arrest and Hypotension in the Emergency Department (SHoC-ED) Investigators. Cureus 10(11): e3624. https://doi. org/10.7759/cureus.3624

26. Littmann L, Bustin D, Haley M. A Simplified and Structured Teaching Tool for the Evaluation and Management of Pulseless Electrical Activity. Medical Principles and Practice. 2014 ;23(1):1-6. https://doi. org/10.1159/000354195

27. Kedan I, Ciozda W, Palatinus JA, Palatinus HN, Kimchi A. Prognostic value of point-of-care ultrasound during cardiac arrest: a systematic review. Cardiovasc Ultrasound. 2020; 13;18(1):1. https://doi.org/10.1186/s12947020-0185-8

28. Jentzer JC, Chonde MD, Shafton A, et al. Echocardiographic left ventricular systolic dysfunction 
early after resuscitation from cardiac arrest does not predict mortality or vasopressor requirements. Resuscitation. 2016; 106:58-64. https:// doi.org/10.1016/j.resuscitation.2016.06.028

29. Jentzer JC, Anavekar NS, Mankad SV, et al. Changes in left ventricular systolic and diastolic function on serial echocardiography after out-ofhospital cardiac arrest. Resuscitation. 2018; 126:1-6. https:// doi.org/10.1016/j.resuscitation.2018.01.050

30. Jentzer JC, Anavekar NS, Mankad SV, et al. Echocardiographic left ventricular diastolic dysfunction predicts hospital mortality after out-of-hospital cardiac arrest. J Crit Care.
2018; 47:114-120. https://doi. org/10.1016/j.jcrc.2018.06.016 31. Song IA, Cha JK, Oh TK, Jo YH, Yoon YE. Two-dimensional echocardiography after return of spontaneous circulation and its association with in-hospital survival after in-hospital cardiopulmonary resuscitation. Sci Rep. 2020; 10(1):11. https://doi.org/10.1038/ s41598-019-56153-z 